\title{
Front Matter: Volume 7848
}

, "Front Matter: Volume 7848," Proc. SPIE 7848, Holography, Diffractive Optics, and Applications IV, 784801 (16 December 2010); doi:

10.1117/12.884287

SPIE. Event: Photonics Asia 2010, 2010, Beijing, China 


\title{
PROCEEDINGS OF SPIE
}

\section{Holography, Diffractive Optics, and Applications IV}

\author{
Yunlong Sheng \\ Chongxiu Yu \\ Linsen Chen \\ Editors
}

\section{8-20 October 2010 \\ Beijing, China}

Sponsored by

SPIE

COS-Chinese Optical Society

\section{Cooperating Organizations}

Beijing Institute of Technology (China) • Beijing University of Posts and Telecommunications (China) Peking University (China) • Tsinghua University (China) • Zhejiang University (China) • Changchun University of Science and Technology (China) • University of Shanghai for Science and Technology (China) • Tianjin University (China) • Nankai University (China) • Capital Normal University (China) Shanghai Institute of Optics and Fine Mechanics (China) • Changchun Institute of Optics and Fine Mechanics (China) • Institute of Semiconductors (China) • Institute of Optics and Electronics (China) Shanghai Institute of Technical Physics (China) • China Instrument and Control Society (China) Optoelectronics Technology Committee, COS (China) • SPIE China Committee (China) • Japan Optical Society (Japan) • Korea Optical Society (Korea, Republic of) • Australia Optical Society (Australia) Singapore Optical Society (Singapore)

\section{Supporting Organizations}

China Association for Science and Technology (China)

National Nature Science Foundation (China)

The Ministry of Science and Technology (China)

Published by

SPIE

Volume 7848 
The papers included in this volume were part of the technical conference cited on the cover and title page. Papers were selected and subject to review by the editors and conference program committee. Some conference presentations may not be available for publication. The papers published in these proceedings reflect the work and thoughts of the authors and are published herein as submitted. The publisher is not responsible for the validity of the information or for any outcomes resulting from reliance thereon.

Please use the following format to cite material from this book:

Author(s), "Title of Paper," in Holography, Diffractive Optics, and Applications IV, edited by Yunlong Sheng, Chongxiu Yu, Linsen Chen, Proceedings of SPIE Vol. 7848 (SPIE, Bellingham, WA, 2010) Article CID Number.

ISSN 0277-786X

ISBN 9780819483782

Published by

SPIE

P.O. Box 10, Bellingham, Washington 98227-0010 USA

Telephone +1 3606763290 (Pacific Time) · Fax +1 3606471445

SPIE.org

Copyright (C) 2010, Society of Photo-Optical Instrumentation Engineers

Copying of material in this book for internal or personal use, or for the internal or personal use of specific clients, beyond the fair use provisions granted by the U.S. Copyright Law is authorized by SPIE subject to payment of copying fees. The Transactional Reporting Service base fee for this volume is $\$ 18.00$ per article (or portion thereof), which should be paid directly to the Copyright Clearance Center (CCC), 222 Rosewood Drive, Danvers, MA 01923. Payment may also be made electronically through CCC Online at copyright.com. Other copying for republication, resale, advertising or promotion, or any form of systematic or multiple reproduction of any material in this book is prohibited except with permission in writing from the publisher. The CCC fee code is 0277-786X/10/\$18.00.

Printed in the United States of America.

Publication of record for individual papers is online in the SPIE Digital Library.

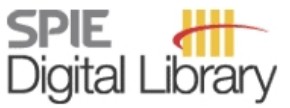

SPIEDigitalLibrary.org

Paper Numbering: Proceedings of SPIE follow an e-First publication model, with papers published first online and then in print and on CD-ROM. Papers are published as they are submitted and meet publication criteria. A unique, consistent, permanent citation identifier (CID) number is assigned to each article at the time of the first publication. Utilization of CIDs allows articles to be fully citable as soon they are published online, and connects the same identifier to all online, print, and electronic versions of the publication. SPIE uses a six-digit CID article numbering system in which:

- The first four digits correspond to the SPIE volume number.

- The last two digits indicate publication order within the volume using a Base 36 numbering system employing both numerals and letters. These two-number sets start with 00, 01, 02, 03, 04, $05,06,07,08,09,0 A, 0 B \ldots 0 Z$, followed by 10-1Z, 20-2Z, etc.

The CID number appears on each page of the manuscript. The complete citation is used on the first page, and an abbreviated version on subsequent pages. Numbers in the index correspond to the last two digits of the six-digit CID number. 


\title{
Contents
}

\author{
xiii Symposium Committees \\ xv Conference Committee \\ xvii Fibre optic systems for gas detection principles, progress, and prospects (Plenary Paper) \\ [7853-150] \\ B. Culshaw, Univ. of Strathclyde (United Kingdom)
}

\section{SESSION 1 DIFFRACTION OF PLASMONIC STRUCTURES}

784802 Resonance mechanism for the electromagnetic enhancement by an isolated subwavelength metallic groove (Invited Paper) [7848-01]

S. Zhang, H. Liu, G. MU, Nankai Univ. (China)

784803 Influence on the luminescence europium complex by localized surface plasmon of silver and gold nanoparticles (Invited Paper) [7848-03]

F. Song, Q. Wang, Nankai Univ. (China) and Key Lab. of Weak Light Nonlinear Photonics, Ministry of Education (China); H. Zhao, Nankai Univ. (China); J. Liu, C. Ming, C. Zhang, J. Tian, J. Xu, Nankai Univ. (China) and Key Lab. of Weak Light Nonlinear Photonics, Ministry of Education (China); S. Lin, E. Y. B. Pun, City Univ. of Hong Kong (Hong Kong, China)

784804 The correlation between single-slit and inter-slit effects in a subwavelength metal double-slit device [7848-04]

X.-L. Zhong, Y.-S. Zhou, Capital Normal Univ. (China); H.-Y. Wang, Tsinghua Univ. (China); F.-H. Wang, Capital Normal Univ. (China)

784805 Beam shaping by the use of plasmonics (Invited Paper) [7848-02]

B. Lee, S. Kim, D. Choi, Seoul National Univ. (Korea, Republic of)

\section{SESSION 2 OPTICAL METROLOGY}

784806 Doppler phase-shifting interferometry and holography (Invited Paper) [7848-05]

T. Yatagai, D. Barada, Utsunomiya Univ. (Japan)

784807 Three-dimensional information encryption with phase extraction and phase shifting interferometry [7848-06]

Y. Shi, Y. Wang, Graduate Univ. of the Chinese Academy of Sciences (China); Y. Yang,

Beijing Univ. of Technology (China); J. Zhang, Graduate Univ. of the Chinese Academy of Sciences (China)

7848 OA 3D tire size code measurement by digital speckle pattern phase shifting interferometry [7848-09]

M. Zhu, Z. Huang, H. Zhang, H. Cai, Tianjin Univ. (China) 
$7848 \mathrm{OB} \quad$ Feasibility of moiré deflectometry for measuring temperature and electron number density of rocket exhaust plume [7848-10]

Y. Chen, Y. Song, Z. Li, A. He, Nanjing Univ. of Science and Technology (China)

\section{SESSION 3 NANO-OPTICS}

7848 OC Efficiency improvement for a polarizing color filter based on submicron metal grating [7848-11]

Y. Ye, H. Zhang, Y. Zhou, S. Shen, L. Chen, Soochow Univ. (China)

7848 OE Efficiency improvement in nanorod amorphous silicon thin film with ultrathin metal electrode for photovoltaic application [7848-13]

C.-C. Chin, Y.-H. Ye, D.-W. Huang, National Taiwan Univ. (Taiwan, China)

7848 OF Surface plasmon resonance imaging biosensor based on silicon photodiode array (Invited Paper) [7848-14]

S. Yin, Institute of Optics and Electronics (China); X. Sun, Institute of Optics and Electronics (China) and Sichuan Univ. (China); Q. Deng, L. Xia, C. Du, Institute of Optics and Electronics (China)

7848 OG Metallic superlens designed with close-to-cutoff of long-range SPP mode [7848-15] G. Tremblay, Y. Sheng, Univ. Laval (Canada)

$7848 \mathrm{OH} \quad$ Microrheology of sodium polystyrene sulfonate (NaPSS) solutions with different polymer concentrations and molecular weights studied by diffusing wave spectroscopy [7848-16] Y.-Q. Chen, National Yang-Ming Univ. (Taiwan, China); C.-Y. Cheng, National Tsing Hua Univ. (Taiwan, China); C.-C. Chiang, National Yang-Ming Univ. (Taiwan, China); M.-T. Wei, Lehigh Univ. (United States); Y.-C. Huang, National Yang-Ming Univ. (Taiwan, China); O. Lavastre, H. Guillaume, D. Guillaume, Univ. de Rennes 1 (France); A. Chiou, National Yang-Ming Univ. (Taiwan, China)

\section{SESSION 4 PHONICS CRYSTALS}

7848 ol Optical properties of two-dimensional square lattice photonic crystal based on holographic polymer-dispersed liquid crystal [7848-17]

A. Y.-G. Fuh, M. S. Li, S.-T. Wu, S.-Y. Huang, H. C. Lin, National Cheng Kung Univ. (Taiwan, China)

\section{SESSION 5 DIFFRACTIVE OPTICS I: DESIGN AND FABRICATION}

7848 OM Properties of Fraunhofer and Fresnel diffraction by a high-order spiral phase plate made by direct laser writing lithography [7848-123]

C. Fan, J. XU, H. Pang, C. Ying, H. Wang, Zhejiang Normal Univ. (China)

784800 Design of an encapsulated fused-silica grating for two-port beam splitting [7848-22]

W. Sun, C. Zhou, Shanghai Institute of Optics and Fine Mechanics (China)

7848 OP Diffraction efficiency analysis of blazed grating fabricated by direct laser writing [7848-23] D. Kuang, Z. Fang, Nankai Univ. (China) 
$78480 Q \quad$ Simulated annealing algorithm applied in adaptive near field beam shaping [7848-24] Z. YU, H. Ma, S. Du, National Univ. of Defense Technology (China)

7848 OR Deep-etched fused silica gratings and applications (Invited Paper) [7848-25]

C. Zhou, Shanghai Institute of Optics and Fine Mechanics (China)

SESSION 6 DIFFRACTIVE OPTICS II: DESIGN AND FABRICATION

7848 OS Fabrication of optical mosaic gratings by consecutive holographic exposures employing a latent-fringe based alignment technique (Invited Paper) [7848-26]

L. Shi, L. Zeng, Tsinghua Univ. (China)

7848 OT Projection photolithography method for fabricating continuous surface structure with aperture less than $10 \mu \mathrm{m}$ [7848-27]

L. Shi, Institute of Optics and Electronics (China) and Univ. of Electronic Science and Technology of China (China); W. Zhang, Institute of Optics and Electronics (China) and Southwest Institute of Applied Magnetics (China); X. Dong, Institute of Optics and Electronics (China); Y. Ye, Univ. of Electronic Science and Technology of China (China); C. Du, Institute of Optics and Electronics (China)

$7848 \mathrm{OU}$ Artificial compound-eye imaging system with a large field of view based on a convex solid substrate [7848-28]

Y. Zhang, Sichuan Univ. (China) and Institute of Optics and Electronics (China); J. Du, Sichuan Univ. (China); L. Shi, X. Dong, X. Wei, C. Du, Institute of Optics and Electronics (China)

7848 OV Fabrication of the convex blazed grating [7848-29]

Q. Liu, H. Wang, P. Sun, J. Wu, Soochow Univ. (China)

7848 OW Fabrication of microstructures on silicon by multiple beam holographic method using nanosecond laser pulses [7848-30]

H. Zhang, Z. Fang, L. Chen, Soochow Univ. (China)

\section{SESSION 7 VOLUME AND DYNAMIC HOLOGRAM STORAGE}

7848 0X Compensation for pixel mismatch based on a three-pixel model in volume holographic data storage [7848-31]

H. Gu, L. Cao, Q. He, G. Jin, Tsinghua Univ. (China)

7848 OY Study of collinear VHS: point spread function and shift selectivity (Invited Paper) [7848-32]

C.-C. Sun, Y.-W. Yu, C.-Y. Cheng, National Central Univ. (Taiwan, China)

784810 Deformation originated from the thermal expansion of volume holograms [7848-34]

C. S. Wu, National Central Univ. (Taiwan, China); C. M. Shih, H. M. Chu, Chung Yuan Christian Univ. (Taiwan, China); T. Y. Chung, Y. W. Yu, C. C. Sun, National Central Univ. (Taiwan, China)

784812 Rewritable collinear holographic image storage with BR-D96N film [7848-36]

A. Ning, N. Menke, S. Yan, Inner Mongolia Univ. (China); N. Hampp, Philipps-Univ. Marburg (Germany) 
784814 Measurement of picosecond laser pulses using an autocorrelator and a FROG apparatus [7848-39]

L. Zhu, Shanghai Institute of Optics and Fine Mechanics (China) and Graduate Univ. of Chinese Academy of Sciences (China); C. Zhou, W. Jia, Shanghai Institute of Optics and Fine Mechanics (China); Z. Fan, Beijing GK Laser Technology Co., Ltd. (China) and The Academy of Opto-Electronics (China); Y. Ma, The Academy of Opto-Electronics (China) and Graduate Univ. of Chinese Academy of Sciences (China); G. Niu, Beijing GK Laser Technology Co., Ltd. (China)

784815 Focal shift and axial dispersion of binary pure-phase filters in focusing systems [7848-40] J. Yu, C. Zhou, W. Jia, A. Hu, Shanghai Institute of Optics and Fine Mechanics (China)

\section{SESSION 9A DIFFRACTIVE OPTICS APPLICATIONS II}

784816 Ultra-high channel-count fiber Bragg grating based on the utilization of the phase-only sampling (Invited Paper) [7848-41]

H. Li, X. Chen, Shizuoka Univ. (Japan)

784817 Linearly chirped supercontinuum for time-stretched analog-to-digital conversion [7848-42] Y. Teng, C. YU, J. Yuan, J. Chen, Beijing Univ. of Posts and Telecommunications (China)

784818 Application to the design of guide-mode resonance grating filter with using simulated annealing method [7848-43]

J. Ma, Y. T. Fan, C. Zhou, S. Wang, H. Cao, Shanghai Institute of Optics and Fine Mechanics (China)

784819 Research on the recording hologram with Foveon in digital color holography [7848-44] Q. Song, Lab. d'Acoustique de l'Univ. du Maine, CNRS (France) and Kunming Univ. of Science and Technology (China); Y. Wu, The Academy of Equipment Command \& Technology (China); P. Tankam, Lab. d'Acoustique de I'Univ. du Maine, CNRS (France); P. Picart, Lab. d'Acoustique de l'Univ. du Maine, CNRS (France) and École Nationale Supérieure d'Ingénieurs du Mans (France); J. Li, Kunming Univ. of Science and Technology (China) and École Nationale Supérieure d'Ingénieurs du Mans (France)

7848 1A Measurement of inner surface profile of a tube using two wavelength phase-shifting digital holography [7848-45]

M. Yokota, T. Adachi, Y. Sakamoto, Shimane Univ. (Japan)

\section{SESSION 9B INTEGRATED IMAGING AND WAVEFRONT ENCODING}

7848 1B Capture of the three-dimensional information based on integral imaging and its sampling analysis (Invited Paper) [7848-52]

J.-H. Park, D. Han, N. Kim, Chungbuk National Univ. (Korea, Republic of)

7848 IE Phase compensation for eliminating black-matrix effect of phase-only spatial light modulator [7848-55]

J. Tian, D. Li, H. Qi, J. Zheng, Shenzhen Univ. (China) 
7848 IF Phase calibration of spatial light modulators by heterodyne interferometry [7848-56]

R. Wang, D. Li, M. Hu, J. Tian, Shenzhen Univ. (China)

\section{SESSION 10A DIGITAL HOLOGRAPHY}

$784811 \quad$ Contrast between the wavelet transform with coefficients selection method and the traditional frequency domain filtering method for digital hologram reconstruction [7848-48] H. Xia, M. Li, M. Tang, Soochow Univ. (China)

$78481 \mathrm{~J}$ Application of phase unwrapping algorithm based on least-squares and iteration in digital holography [7848-49]

H. Xia, R. Guo, Z. Fan, X. Qian, B. Yang, Kunming Univ. of Science and Technology (China)

$78481 \mathrm{~K} \quad$ Study of color digital holography of large size object with zero-order elimination [7848-50]

J. Gui, J. Li, Y. Zhang, Y. Lou, Z. Fan, Kunming Univ. of Science and Technology (China)

$78481 \mathrm{~L} \quad$ Optimization research for digital hologram recording system of big objects [7848-51]

Y. Lou, J. Li, Y. Zhang, J. Gui, C. Li, Z. Fan, Kunming Univ. of Science and Technology (China)

\section{SESSION 10B OPTICAL DISPLAY}

$78481 \mathrm{M} \quad$ Analysis on the 3D crosstalk in stereoscopic display (Invited Paper) [7848-57]

H.-J. Choi, Sejong Univ. (Korea, Republic of)

$78481 \mathrm{~N} \quad$ Resonant diffraction grating designed for beam splitting and color separation in Fresnel diffraction region [7848-58]

Y. Fang, Q. Tan, G. Jin, Tsinghua Univ. (China)

784810 Depth-fused three-dimensional display using polarization distribution [7848-59]

S. Park, S.-W. Min, Kyung Hee Univ. (Korea, Republic of)

7848 1P Laser imaging method using computational holography [7848-60]

T. Wang, Y. YU, H. Zheng, Shanghai Univ. (China)

\section{POSTER SESSION}

$78481 Q \quad$ A novel method for mapping two-dimensional polarization distribution [7848-61]

C.-H. Niu, X.-H. Mao, Beijing Information Science \& Technology Univ. (China)

7848 IR Numerical study on radially polarized beam focusing through dielectric interface and metallic film [7848-62]

X. Gao, L. Ning, Guilin Univ. of Electronic Technology (China); X. Gan, Swinburne Univ. of Technology (Australia)

7848 is Theoretical and experimental analysis of Maxwell fish-eye spherical lens diffraction intensity [7848-63]

Z. Cai, H. Lv, A. Liu, J. Tong, X. Yi, Q. Li, X. Wang, Y. Ding, Xiaogan Univ. (China) 
$78481 \mathrm{U}$ Glasses-free 3D display system using grating film for parallax image separation [7848-65] K. Sakamoto, M. Kuwata, Konan Univ. (Japan)

7848 IV Fabrication of photonic crystals using holography and study for the lattice constant changes [7848-66]

J. Han, H. Zhang, T. Zhao, Capital Normal Univ. (China)

$78481 \mathrm{X} \quad$ Shape the unstable laser beam using diffractive optical element array [7848-68]

Y. Li, C. Qiu, L. Pan, T. Xing, W. Lin, C. Zhou, Institute of Optics and Electronics (China)

7848 IY Eliminating zero-order diffraction in the digital holography wavefront reconstruction with adjustable magnification [7848-69]

J. Li, Kunming Univ. of Science and Technology (China) and École Nationale Supérieure d'Ingénieurs du Mans (France); Q. Song, Lab. d'Acoustique de I'Univ. du Maine, CNRS (France) and Kunming Univ. of Science and Technology (China); P. Tankam, Lab. d'Acoustique de l'Univ. du Maine, CNRS (France); P. Picart, Lab. d'Acoustique de l'Univ. du Maine, CNRS (France) and École Nationale Supérieure d'Ingénieurs du Mans (France)

784812 Application of the angular spectrum diffraction transform in the design of binary optical element [7848-70]

Y. Wu, The Academy of Equipment Command \& Technology (China); J. Li, Kunming Univ. of Science and Technology (China)

784820 4-views flat tabletop display using prism film for viewing angle control [7848-71]

K. Sakamoto, T. Honda, Konan Univ. (Japan)

$784821 \quad$ The scattering characteristic of diffractive optics [7848-72]

W. Jia, Y. Wang, F. Huang, J. Hou, Mechanical Engineering College (China)

784822 Analysis on light intensity distribution of diffraction of "unequal slit width" gratings [7848-73] $X$. Wang, Beijing Technology and Business Univ. (China); Z. Hong, Shandong Normal Univ. (China); X. Li, Beijing Technology and Business Univ. (China)

784823 Design and analysis of waveguide grating coupling with gradually changing periods for optical interconnection [7848-74]

$X$. Feng, National Univ. of Defense Technology (China) and Information Engineering Univ. (China); J. Ji, W. Dou, National Univ. of Defense Technology (China)

784824 Modeling and characterization of tunable photonic crystal waveguides based on two-dimensional periodic arrays of silicon pillars [7848-75]

H. Butt, Q. Dai, T. D. Wilkinson, G. A. J. Amaratunga, Univ. of Cambridge (United Kingdom)

784825 Multi-image hiding method based on polarization multiplexing digital holography [7848-76] Z. Zhu, S. Feng, S. Nie, J. Zhang, Nanjing Normal Univ. (China)

784826 Single-exposure color digital holography [7848-77]

S. Feng, Y. Wang, Z. Zhu, S. Nie, Nanjing Normal Univ. (China)

784827 Improved algorithm for diffraction calculation [7848-78]

X. Wang, C. Li, S. Yuan, Kunming Univ. of Science and Technology (China) 
784828 Optimization of multiplexed holograms for multidimensional tomographic imaging [7848-79]

L. Song, Z. Jiang, Z. Xu, J. Yang, Beijing Univ. of Technology (China)

784829 Subwavelength focusing of nanopatterned photon sieves [7848-80]

Y. Xue, W. Ge, C. Wang, B. Cao, Soochow Univ. (China)

7848 2A Tunable volume holographic filter based on the photorefractive grating [7848-81] M. Zhang, H. Meng, Z. Le, Zhejiang Univ. of Technology (China)

7848 2B Controlling the propagating features of light through two-dimensional coupled-cavity photonic crystal waveguides [7848-82]

S. Feng, L. Ao, Y. Wang, Minzu Univ. of China (China)

7848 2C Micro-spectrometer based on flat field holographic concave grating [7848-83]

C. Li, X. Chen, J. Wu, Z. Hu, Soochow Univ. (China)

7848 2D Position of virtual image formed by bi-grating imaging [7848-84]

W. Zhang, T. Luo, G. Huang, Y. Xiao, X. LU, Guangxi Univ. (China)

$78482 \mathrm{E} \quad$ Off-axis reflection digital holographic microscopy for micron structure tomography measurement [7848-85]

G. Cheng, Z. Jiang, D. Wang, M. Ding, H. Cui, Beijing Univ. of Technology (China)

$78482 \mathrm{~F}$ Label stacking of the time-stacked SAC labels in optical packet switching with a simple label recognition based on FWM [7848-86]

Y. Shi, Q. Zhang, C. Yu, X. Xin, Beijing Univ. of Posts and Telecommunications (China)

$78482 \mathrm{G}$ A new method of calculating the diffraction efficiency for diffraction/refraction infrared hybrid system [7848-87]

T. Wang, J. Bai, Y. Liang, X. Hou, Zhejiang Univ. (China)

$78482 \mathrm{H} \quad$ Air impurity in holographic photonic crystals made with dichromated gelatin [7848-88] Z. Ren, S. Li, North China Electric Power Univ. (China); D. Liu, Beijing Normal Univ. (China)

$784821 \quad$ Diffraction intensity analysis of a transmission prism grating [7848-89]

X. Liu, Harbin Engineering Univ. (China); G. Zhang, Beijing Institute of Graphic Communication (China)

$78482 \mathrm{~J}$ Characteristics analysis of a transmission prism grating based on blazed gratings [7848-90] G. Zhang, Beijing Institute of Graphic Communication (China); X. Liu, Harbin Engineering Univ. (China)

7848 2K A novel structure photonic crystal fiber based on bismuth-oxide for optical parametric amplification [7848-91]

C. Jin, J. Yuan, C. Yu, Beijing Univ. of Posts and Telecommunications (China)

$78482 \mathrm{~L} \quad$ Sub-wavelength metal polarization gratings array used in polarization imaging [7848-92]

P. Sun, Q. Liu, J. WU, Soochow Univ. (China) 
7848 2N Reference wavefront reconstruction based on spatial light modulator [7848-94]

N. Liang, M. Hu, R. Guo, S. Lu, Xi'an Technological Univ. (China)

784820 Characteristics of subwavelength photolithography based on surface plasmon polaritons [7848-95]

W. Ge, Y. Xue, C. Wang, B. Cao, Soochow Univ. (China)

7848 2P Multiple binary images hiding with bit-plane composition and jigsaw transform [7848-96]

Y. Shi, Y. Wang, Graduate Univ. of the Chinese Academy of Sciences (China); Y. Yang,

Beijing Univ. of Technology (China); J. Zhang, Graduate Univ. of the Chinese Academy of

Sciences (China)

$78482 \mathrm{Q} \quad$ Multiple-image encryption with spatial information prechoosing and cascaded blocks scrambling [7848-97]

Y. Yang, Beijing Univ. of Technology (China); Y. Wang, Y. Shi, J. Zhang, Graduate Univ. of the Chinese Academy of Sciences (China); W. Hao, Beijing Univ. of Technology (China)

$78482 \mathrm{R}$ Comparative research on the crosstalk characteristics of acoustic-optic tunable filters with different bandwidth used in the communication [7848-98]

W. Liu, Capital Normal Univ. (China); L. Ban, Y. Sun, Beijing Institute of Technology (China)

$78482 \mathrm{~S} \quad$ Bi-grating imaging by computer simulating [7848-99]

W. Zhang, Y. Xiao, X. Huang, L. Wan, Q. Yang, Guangxi Univ. (China)

7848 2T OCDMA over WDM PON system using DQPSK modulation and balanced detection [7848-100]

F. Deng, Q. Zhang, C. Yu, Beijing Univ. of Posts and Telecommunications (China)

$78482 \mathrm{U}$ Design and simulation of a polarized color filter based on sub-wavelength metal gratings [7848-101]

Y. Zhang, Y. Zhou, L. Chen, Soochow Univ. (China)

7848 2V Application of digital holography in temperature distribution measurement [7848-102] G. Wang, Beijing Univ. of Technology (China) and Henan Institute of Metrology (China); Y. Li, D. Wang, J. Zhao, Beijing Univ. of Technology (China)

7848 2W Diffraction spectrum of variable line space plane grating at oblique incidence [7848-103] Y. Luo, J. Lou, Y. Liu, W. Tian, China Jiliang Univ. (China)

$78482 \mathrm{X} \quad$ High-resolution holographic imaging technology by microscopic image plane holography [7848-104]

X. Wang, Handan College (China); W. Gong, F. Liu, H. Wang, Hebei Univ. of Engineering (China)

$78482 Z$ Cell imaging techniques based on digital image plane holography [7848-106] Z. Chen, Handan College (China); W. Gong, F. Liu, H. Wang, Hebei Univ. of Engineering (China)

784830 Study on the unweighted least-squares phase unwrapping algorithm [7848-107] X. Wang, Handan College (China); Z. Zhang, Z. Guo, H. Wang, Hebei Univ. of Engineering (China) 
784831 Computer generated holograms of 3D objects with reduced number of projections [7848-108]

S. Huang, D. Liu, J. Zhao, Shanghai Univ. (China)

784832 Reduction of speckle noise in digital holography by using of multiple holograms [7848-109] Z. Chen, Handan College (China); Z. Guo, Z. Zhang, H. Wang, Hebei Univ. of Engineering (China)

784834 Microscopy based on digital lensless Fourier transforms holography [7848-111] Z. Chen, Handan College (China); F. Liu, W. Gong, H. Wang, Hebei Univ. of Engineering (China)

784836 Performance of volume phase holographic transmission grating recorded in DCG for PGP [7848-113]

M. Li, M. Tang, H. Xia, C. Fang, J. Wu, X. Zhao, Soochow Univ. (China)

784837 40-Gbit/s PON over OCDMA uplink using DQPSK/OOK orthogonal remodulation [7848-1 14] J. Chen, Q. Zhang, C. YU, X. Xin, Y. Shi, F. Deng, C. Jin, Beijing Univ. of Posts and Telecommunications (China)

784838 Study on the polarization grating working in 1053-nm wavelength [7848-115] Q. Liu, P. Sun, H. Wang, J. Wu, Soochow Univ. (China)

784839 Eight-channel Fourier transform computer generated holograms [7848-116] R. Guo, Xi'an Technological Univ. (China), Xi'an Institute of Optics and Precision Mechanics (China), and Graduate School of the Chinese Academy of Sciences (China); B. Yao, Xi'an Institute of Optics and Precision Mechanics (China); J. Han, S. Lu, C. Duan, Xi'an Technological Univ. (China); F. Wang, Beijing Institute of Technology (China)

7848 3B The Monte Carlo simulation of focused Gaussian beam for the aberration systems [7848-118] S. Li, X. Cui, Y. Niu, D. Zhang, J. Zhu, Y. Zhang, F. Li, Tibet Institute for Nationalities (China)

7848 3C Application of fractal masks to determination phase discontinuities in transparent objects [7848-1 19]

A. A. Zinchik, Y. B. Muzychenko, S. Stafeev, Univ. of Information Technologies, Mechanics and Optics (Russian Federation)

7848 3D Focusing properties of fractal phase-type zone plates [7848-120] Y. B. Muzychenko, A. A. Zinchik, S. Stafeev, Univ. of Information Technologies, Mechanics and Optics (Russian Federation)

7848 3E An FPGA-based controlling and data acquisition scheme for the demodulation of quasi-distributed FBG sensing system [7848-121]

R. Yu, Y. Wang, K. Wang, Beijing Univ. of Posts and Telecommunications (China)

$78483 \mathrm{G}$ Analysis and control of thin film stresses during extreme ultraviolet lithography mask blank fabrication [7848-124]

L. Zheng, Harbin Institute of Technology (China) 
$78483 \mathrm{H} \quad$ Investigation and prediction of image placement errors in extreme ultraviolet lithography masks [7848-125]

L. Zheng, Harbin Institute of Technology (China)

Author Index 


\title{
Symposium Committees
}

\author{
General Chairs
}

Ralph James, Brookhaven National Laboratory (United States)

Bingkun Zhou, Tsinghua University (China)

General Cochairs

Arthur Chiou, National Yang-Ming University (Taiwan, China)

Zhizhan Xu, Shanghai Institute of Optics and Fine Mechanics (China)

Jianlin Cao, China Ministry of Science and Technology (China)

Junhao Chu, Shanghai Institute of Technical Physics (China)

Honorary Chairs

Daheng Wang, Chinese Academy of Sciences (China)

Guoguang Mu, Nankai University (China)

Technical Program Chair

Songlin Zhuang, Shanghai University of Science and Technology (China)

Technical Program Cochairs

Qiming Wang, Institute of Semiconductors (China)

Xu Liu, Zhejiang University (China)

Qihuang Gong, Peking University (China)

Yimo Zhang, Tianjin University (China)

Local Organizing Committee Chair

Shusen Xie, Fujian Normal University (China)

Local Organizing Committee Cochairs

Guoqiang Ni, Beijing Institute of Technology (China)

Xiaomin Ren, Beijing University of Posts and Telecommunications (China)

Daoyin Yu, Tianjin University (China)

Ying Gu, PLA General Hospital (China)

Huilin Jiang, Changchun University of Science and Technology (China) 
General Secretary

Guoqiang Ni, Beijing Institute of Technology (China)

Administrative Vice General Secretary

Boyu Ding, Beijing Institute of Technology (China)

Vice General Secretaries

Hanyi Zhang, Tsinghua University (China)

Ya Cheng, Shanghai Institute of Optics and Fine Mechanics (China)

Zhongwei Fan, Academy of Opto-electronics (China)

Jianxin Chen, Fujian Normal University (China)

Lan Wu, Zhejiang University (China)

Jianping Zhang, Chinese Optical Society (China)

Local Organizing Committee

Chongxiu Yu, Beijing University of Posts and Telecommunications

(China)

Hongda Chen, Institute of Semiconductors (China)

Yuejin Zhao, Beijing Institute of Technology (China)

Kangnan Qi, Beijing Optical Society (China)

Chunqing Gao, Beijing Institute of Technology (China)

Tiegen Liu, Tianjin University (China)

Xiaocong Yuan, Nankai University (China)

Weiming Chen, Chongqing University (China)

Lanxing Shao, Shanghai Optical Society (China)

Baosheng Liu, Beijing Optical Society (China)

Xin Wang, Hubei Optical Society (China)

Lin Zhai, Chinese Optical Society (China) 


\title{
Conference Committee
}

\author{
Conference Chairs \\ Yunlong Sheng, Université Laval (Canada) \\ Chongxiu Yu, Beijing University of Posts and Telecommunications \\ (China) \\ Linsen Chen, Soochow University (China)
}

Program Committee

Chunlei Du, Institute of Optics and Electronics (China)

Min Gu, Swinburne University of Technology (Australia)

Anzhi He, Nanjing University of Science \& Technology (China)

Dahsiung Hsu, Beijing University of Posts and Telecommunications (China)

Byoungho Lee, Seoul National University (Korea, Republic of)

Junchang Li, Kunming University of Science and Technology (China)

Hoang-Yan Lin, National Taiwan University (Taiwan, China)

Ai-Qun Liu, Nanyang Technological University (Singapore)

Dahe Liu, Beijing Normal University (China)

Hai Ming, University of Science and Technology of China (China)

Ting-Chung Poon, Virginia Polytechnic Institute and State University (United States)

Ching-Cherng Sun, National Central University (Taiwan, China)

Toyohiko Yatagai, University of Tsukuba (Japan)

Xiaocong Yuan, Nankai University (China)

Jianlin Zhao, Northwestern Polytechnical University (China)

Changhe Zhou, Shanghai Institute of Optics and Fine Mechanics

(China)

Session Chairs

1 Diffraction of Plasmonic Structures

Yunlong Sheng, Université Laval (Canada)

2 Optical Metrology

Dahe Liu, Beijing Normal University (China)

3 Nano-Optics

Chunlei Du, Institute of Optics and Electronics (China)

4 Phonics Crystals

Toyohiko Yatagai, Utsunomiya University (Japan) 
5 Diffractive Optics I: Design and Fabrication

Chongxiu Yu, Beijing University of Posts and Telecommunications

(China)

6 Diffractive Optics II: Design and Fabrication

Guoqiang Li, University of Missouri-St. Louis (United States)

$7 \quad$ Volume and Dynamic Hologram Storage

Linsen Chen, Soochow University (China)

8 Diffractive Optics Applications I

Changhe Zhou, Shanghai Institute of Optics and Fine Mechanics (China)

9A Diffractive Optics Applications II

Jiabi Chen, University of Shanghai for Science and Technology (China)

9B Integrated Imaging and Wavefront Encoding

Ching-Cherng Sun, National Central University (Taiwan, China)

10A Digital Holography

Hongpu Li, Shizuoka University (Japan)

10B Optical Display

Xiaocong Yuan, Nankai University (China) 